amniotic fluid cells

cerebroside sulfate loading test metachromatic leukodystrophy prenatal diagnosis

pseudo arylsulfatase A deficiency

\title{
Prenatal Diagnosis of Metachromatic Leukodystrophy in a Family with Pseudo Arylsulfatase A Deficiency by the Cerebroside Sulfate Loading Test
}

\author{
HAYATO KIHARA, ${ }^{(27)}$ CHEN-KUNG HO, ARVAN L. FLUHARTY, KATHERINE K. TSAY, AND \\ PATRICIA L. HARTLAGE \\ UCLA School of Medicine, Neuropsychiatric Institute-Pacific State Hospital Research Group, Pomona, California \\ [H. K., A. L. F., K. K. T.] and Medical College of Georgia, Augusta, Georgia [C. K. H., P. L. H.] USA
}

\begin{abstract}
Summary
Prenatal diagnosis was requested by a family at risk for metachromatic leukodystrophy (MLD). An examination of the family leukocyte arylsulfatase $A$ profile revealed that the mother had pseudo arylsulfatase $A$ deficiency. Cultured amniotic fluid cells were deficient in arylsulfatase $A$, so two possibilities were indicated: the fetus was affected with MLD or had the pseudodeficiency phenotype. The only known biochemical test to differentiate the two enzyme deficient phenotypes is cerebroside sulfate loading of growing fibroblasts. The pseudodeficient cells hydrolyze the incorporated sulfatide as efficiently as control cells, whereas MLD cells show no hydrolysis. Application of this test to the at risk cultured amniotic fluid cells resulted in appreciable uptake of the sulfolipid, but no hydrolysis. Control amniotic fluid cell cultures hydrolyzed 82 to $95 \%$ of the incorporated sulfatide. Therefore, an affected fetus was indicated. Fibroblasts derived from the aborted fetus showed a deficiency of arylsulfatase $A$ and a similar inability to hydrolyze cerebroside sulfate in the loading test. The loading technique allowed the prenatal diagnosis of MLD when the arylsulfatase $A$ analysis was equivocal.
\end{abstract}

\section{Speculation}

In metachromatic leukodystrophy families with pseudo arylsulfatase $A$ deficiency, the usual enzyme assays on cultured amniotic fluid cell extracts fail to differentiate between the fetus with the affected phenotype and the fetus with the pseudodeficiency phenotype. The cerebroside sulfate loading test in growing cultured amniotic fluid cells allowed this discrimination. It is important to examine the family enzyme profile for the pseudodeficiency phenotype as a prerequisite in the prenatal diagnosis of metachromatic leukodystrophy to avoid the erroneous identification of a pseudodeficient fetus as a metachromatic leukodystrophy fetus.

In metachromatic leukodystrophy (MLD), the profound deficiency of arylsulfatase A (arylsulfate sulfohydrolase, EC 3.1.6.1) leads to the accumulation of cerebroside sulfate in neural tissue resulting in progressive neurological degeneration (5). Based on the age of onset of symptoms, three classical types of MLD are recognized: late infantile, juvenile, and adult. Each type appears to be an independent autosomal recessive disorder, so allelism is implied. Although no treatment is available, the disorder can be prevented in at risk families because MLD is amenable to prenatal diagnosis. In affected pregnancies, cultured amniotic fluid cells are deficient in arylsulfatase $A(10,14,17,21-24)$.

Dubois et al. $(3,4)$, Lott et al. (15), and Fluharty et al. (8) described four MLD families in which one of the parents and some of the unaffected children had very low arylsulfatase $A$ activities which overlapped the range of probands. These individuals showed no neurologic dysfunction and were healthy, so it would be appropriate to typify the apparent enzyme deficiency as a pseudodeficiency. The attenuated enzyme activity was observed in leukocyte and fibroblast extracts whether the activity was assessed with the artificial substrate, nitrocatechol sulfate, or with the physiological substrate, cerebroside sulfate. The usual enzyme assay techniques thus did not differentiate the pseudodeficient subjects from the probands. Usually, this is no cause for concern. However, there is concern when there is a pregnancy in such a family (15). Application of the usual criterion for an affected fetus in prenatal diagnosis, the deficiency of arylsulfatase $A$ in cultured amniotic fluid cells, could lead to the termination of the pregnancy of an unaffected fetus.

A similar biochemical paradox occurs in the three classical types of MLD. The usual enzyme assays show a uniform profound deficiency of arylsulfatase A (20). The three types, however, were differentiated by cerebroside sulfate loading of growing fibroblasts. Control cells with a normal complement of arylsulfatase $\mathbf{A}$ hydrolyzed the intracellularly incorporated sulfatide; late infantile MLD cells showed no hydrolysis, adult MLD cells showed about half-normal hydrolysis, and juvenile MLD cells showed intermediate hydrolysis between late infantile and adult cells (20). The application of the cerebroside sulfate loading test to fibroblasts of an MLD heterozygote with pseudo arylsulfatase $A$ deficiency showed unimpaired ability to hydrolyze the sulfolipid (8). The rate was identical to that of control fibroblasts. The cells of the affected daughter showed no hydrolysis. The loading test thus allowed unequivocal biochemical differentiation of the two phenotypes.

This report is concerned with a fifth MLD family with a pseudo arylsulfatase A-deficient parent and the application of the cerebroside sulfate loading test in cultured amniotic fluid cells for prenatal assessment of the fetal phenotype.

\section{CASE REPORT}

The diagnosis of late infantile MLD was established in the proband, a white female, at age 28 months, based on clinical features, decreased nerve conduction velocity, accumulation of metachromatic material in sural nerve, and profound deficiency of arylsulfatase $A$ in leukocytes and urine (Table 1). The father, then 29 years old, and the mother, 27 years old, were nonconsanguineous and in good health. The mother was in the 10th week of pregnancy when her daughter's diagnosis was established. Genetic counseling was provided, and the couple requested prenatal diagnosis. Arylsulfatase $A$ determinations on leukocytes and urine 
from the couple revealed a severe deficiency in the mother's leukocytes (cf. Table 1). Fibroblast cultures were initiated on the three family members, but sufficient outgrowths were not attained before the prenatal diagnosis was attempted. However, in subsequent studies, the mother's cells were used to confirm her pseudodeficiency status, and the proband cells provided reference values for fetal fibroblasts.

Amniocentesis was performed at 13 weeks of gestation. In the 17th week, cultured amniotic fluid cells showed a 46, XY karyotype and no detectable arylsulfatase $A$ activity (Table 2 ). The remaining cells were further cultured and examined in the 19th week by cerebroside sulfate loading. Counseling on the basis of the results of the latter test led to parental decision to terminate the pregnancy. A male fetus of 20 weeks gestational age was delivered following an intraamniotic infusion of prostaglandin$F_{2 \alpha}$. Selected tissue specimens were placed in culture, frozen at $-60^{\circ} \mathrm{C}$, or processed for histologic examination.

\section{MATERIALS AND METHODS}

\section{CELL CULTURES}

Amniotic fluid cells were cultured in Ham's F-10 medium with $25 \mathrm{mM} N$-2-hydroxyethylpiperazine- $N^{\prime}$-2-ethanesulfonic acid (HEPES) and $17 \%$ fetal calf serum. Control cultures which had been in culture for approximately the same period of time as the present at risk culture were from pregnancies at risk for cytogenetic defects but showed normal karyotypes. An attempt was made to have roughly equal numbers of cells in test and control flasks, but differences in growth patterns made this difficult. Skin fibroblasts were cultured in Eagle's minimum essential medium with $25 \mathrm{mM}$ $N$-2-hydroxyethylpiperazine- $N^{\prime}$-2-ethanesulfonic acid and $10 \%$ fetal calf serum.

\section{${ }^{35}$ S]CEREBROSIDE SULFATE-LOADING MEDIUM}

The basic medium was medium 199 with Earle's salts, $26 \mathrm{mM}$ $\mathrm{NaHCO}_{3}$, and $10 \%$ fetal calf serum. Appropriate amounts of ${ }^{35} \mathrm{~S}$ labeled rat brain cerebroside sulfate (6) and unlabeled beef brain cerebroside sulfate (Supelco, Inc., Bellafonte, PA), each dissolved in chloroform:methanol $(2: 1 \mathrm{v} / \mathrm{v})$ containing $5 \%$ water, were dispensed in a flask to yield a final concentration of $0.024 \mathrm{mM}$

Table 1. Arylsulfatase A activities of family members

\begin{tabular}{llc} 
& \multicolumn{2}{c}{ Arylsulfatase A } \\
\cline { 2 - 3 } \multicolumn{1}{c}{ Subject } & Leukocyte' & Urine $^{2}$ \\
\hline Proband & 0 & 1.2 \\
Mother & 2.6 & 93.4 \\
Father & 28.1 & 23.0 \\
Control $^{3}$ & $106.1 \pm 7.8^{4}$ & $123.3 \pm 27.5$ \\
\hline
\end{tabular}

' nmoles of substrate hydrolyzed per hr per $\mathrm{mg}$ protein.

${ }^{2}$ nmoles of substrate hydrolyzed per hr per $\mathrm{ml}$ in $24-\mathrm{hr}$ specimens.

${ }^{3}$ Six subjects for leukocytes; 4 subjects for urine.

4 Mean \pm S.D.

Table 2. Arysulfatase A activity of cultured amniotic fluid cells

\begin{tabular}{lcc} 
& Cells & Arylsulfatase $A^{1}$ \\
\hline Fetus at risk & 0 \\
Control 1 & 164 \\
Control 2 & 155 \\
\hline
\end{tabular}

' nmoles of substrate hydrolyzed per hr per mg protein. containing 30 to $40,000 \mathrm{cpm} / \mathrm{ml}$ when compounded with the medium. The chloroform:methanol was evaporated under a stream of nitrogen, care being taken to remove all the organic solvent while avoiding complete drying of the sulfatide. (Completely dried sulfatide is difficult to disperse in the medium). Medium was then added to the flask. The sulfatide was dispersed by stirring for 2 to $3 \mathrm{hr}$, and the resulting solution was sterilized by membrane filtration (RA $1.2 \mu \mathrm{m}$ membrane; Millipore Corp., Bedford, MA). The radioactivity of the filtered medium was determined to be assured that no excessive loss of cerebroside sulfate had occurred. An $\left[{ }^{35}\right.$ S]inorganic sulfate analysis was done at this time to establish medium baseline radioactivity.

\section{CEREBROSIDE SULFATE LOADING TEST}

The test has been modified somewhat from that originally described (19). With fibroblasts the Eagle's minimal essential medium of confluent cultures was replaced with medium 199 and cultures were incubated in a $5 \% \mathrm{CO}_{2}$ :atmosphere 2 to 4 days before subculture. An appropriate number of cells to yield a confluent monolayer were plated in T-25 flasks. After 1 to 2 days, the medium was replaced with $3.5 \mathrm{ml}$ of the cerebroside sulfatecontaining medium. The medium was sampled $(0.2 \mathrm{ml})$ periodically for $\left[{ }^{35} \mathrm{~S}\right]$ inorganic sulfate analysis, and at the end of the test period, the cells were analyzed for intracellular sulfatide. In the case of the cultured amniotic fluid cells, the F-10 medium was replaced with medium 199, and the cells were allowed to adjust for one day before initiation of the loading test. Cell distribution was typically more uneven and sparse than in fibroblast cultures.

The $\left[{ }^{35} \mathrm{~S}\right]$ inorganic sulfate was determined after removal of $\left[{ }^{35} \mathrm{~S}\right]$ sulfatide in the medium by an extraction procedure adapted from Folch et al. (9). Specifically, $0.05 \mathrm{ml} 0.12 \mathrm{M} \mathrm{NaCl}$ containing 0.4 $\mathrm{mM} \mathrm{Na}_{2} \mathrm{SO}_{4}$ as a carrier and $1 \mathrm{ml}$ chloroform:methanol $(2: 1 \mathrm{v} / \mathrm{v})$ were added to the $0.2 \mathrm{ml}$ sample. The mixture was shaken vigorously and phase separation facilitated by centrifugation. The upper (aqueous) phase was washed with $0.2 \mathrm{ml}$ "technical lower phase" (chloroform:methanol:0.1 M NaCl, 86:14:1, by volume). Radioactivity was determined on a $0.2 \mathrm{ml}$-aliquot (one-half of the sample) of the washed upper phase.

Cells were harvested by trypsinization and scraping. (Medium cerebroside sulfate is frequently trapped in the extracellular matrix, so harvesting by scraping only can yield erroneously high values for intracellular sulfatide.) The cells were washed twice with saline, and the cell pellet was dried under a gentle stream of air for 15 to $20 \mathrm{~min}$. The dried cells were extracted with $0.2 \mathrm{ml}$ chloroform:methanol $(2: 1, \mathrm{v} / \mathrm{v})$. A $0.1-\mathrm{ml}$ aliquot (one-half of the sample) of the extract which contained the intracellular cerebroside sulfate was counted. The sum of the $\left[{ }^{35} S\right]$ inorganic sulfate elaborated into the medium and intracellularly accumulated sulfatide was taken as the total sulfatide incorporated by the cells. The debris from the extraction was dissolved by standing overnight in $0.1 \mathrm{ml} 2.5 \mathrm{~N} \mathrm{NaOH}$, neutralized with $0.1 \mathrm{ml} 2.5 \mathrm{~N}$ acetic acid, and assayed for protein (16).

\section{ENZYME ASSAYS}

Arylsulfatase A activities of leukocyte, cultured amniotic fluid cell, tissue and fibroblast extracts and of urine were determined essentially by the procedure of Baum et al. (1). Fibroblast extracts were also examined for cerebroside sulfatase activity after dialysis by a modification (7) of the procedure of Porter et al. (18).

\section{RESULTS}

CEREBROSIDE SULFATE-LOADING OF CULTURED AMNIOTIC FLUID CELLS

The results of the cerebroside sulfate loading in cultured amniotic fluid cells are shown in Fig. 1. Control cells hydrolyzed 82 to $95 \%$ of the incorporated sulfatide by day 5 . Both flasks of the 
at risk cells showed no hydrolysis. At the end of the test period, the control cells contained only small amounts of cerebroside sulfate (Table 3 ). The at-risk cells contained substantial amounts of sulfatide. The latter observation was important because it indicated that the lack of hydrolysis was due to absence of functional enzyme rather than a generalized metabolic failure which prevented incorporation of the exogenous cerebroside sulfate.

\section{FETAL TISSUE}

Analysis of fetal tissue showed reduced arylsulfatase $\mathbf{A}$ activity in liver and no detectable activity in brain or kidney (Table 4). The control tissue was not age matched. However, the enzyme activities were comparable to those we have observed on separate occasions in fetal tissue of similar gestational age (11).

\section{FIBROBLAST STUDIES}

Arylsulfatase $A$ and cerebroside sulfatase activities of cultured fibroblasts are summarized in Table 5 . The cells of the proband and fetus had very low activities by both assays. The mother's cells had slightly higher activities but were still in the range usually considered diagnostic for MLD. The father's cells had activities in the typical MLD heterozygote range.

In the cerebroside sulfate-loading test, the proband and fetal fibroblasts showed no hydrolysis (Fig. 2) with extensive sulfatide accumulation (Table 6). Both the mother's and the father's fibroblasts showed normal hydrolysis with minimal sulfatide accumulation. The fibroblast studies confirmed the pseudodeficiency status of the mother. More importantly, they confirmed the prenatal diagnosis of MLD.

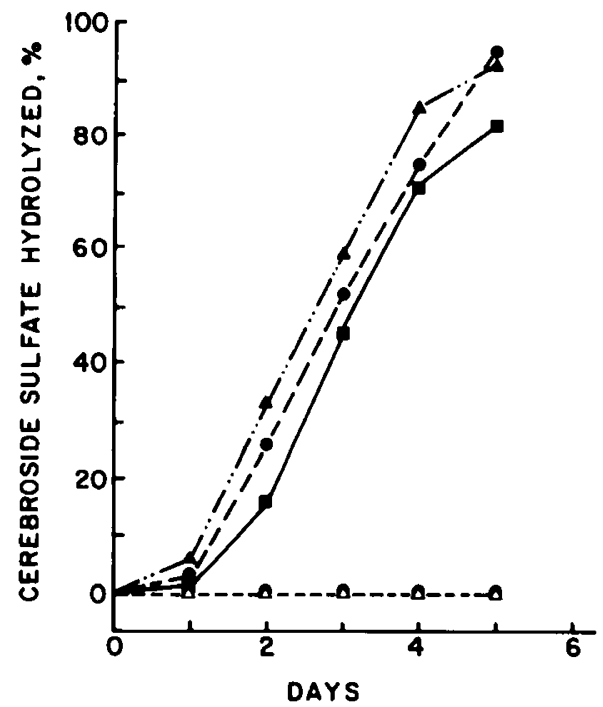

Fig. 1. The response of growing cultured amniotic fluid cells to the cerebroside sulfate-loading test. Fetus at risk flask $I(\Delta)$; fetus at risk flask $2(\mathrm{O})$; control 1 (A); control $2(\Theta)$; control $3(\square)$

Table 3. Intracellular cerebroside sulfate of cultured amniotic fluid cells after the loading test

\begin{tabular}{|c|c|}
\hline Cells & Cerebroside sulfate ${ }^{\prime}$ \\
\hline \multicolumn{2}{|l|}{ Fetus at risk } \\
\hline Flask 1 & 19.6 \\
\hline Flask 2 & 20.0 \\
\hline Control 1 & 1.7 \\
\hline Control 2 & 1.4 \\
\hline Control 3 & 1.8 \\
\hline
\end{tabular}

\footnotetext{
' nmoles/mg protein.
}

Table 4. Arylsulfatase $A$ activities of fetal organs

\begin{tabular}{lcc}
\hline & \multicolumn{2}{c}{ Arylsulfatase $\mathrm{A}^{1}$} \\
\cline { 2 - 4 } \multicolumn{1}{c}{ Organ } & Fetus $^{2}$ & Control $^{3}$ \\
\hline Liver & 25.2 & 125.3 \\
Kidney & 0 & 66.0 \\
Brain & 0 & 19.3 \\
\hline
\end{tabular}

' nmoles of substrate hydrolyzed per $\mathrm{mg}$ protein.

${ }^{2}$ Stored 17 days at $-60^{\circ} \mathrm{C}$.

${ }^{3}$ Fourteen-year-old female. Stored 150 days at $-60^{\circ} \mathrm{C}$.

Table 5. Enzyme activity of fibroblast extracts

\begin{tabular}{|c|c|c|}
\hline Cells & Arylsulfatase $A^{\prime}$ & $\begin{array}{c}\text { Cerebroside } \\
\text { sulfatase }\end{array}$ \\
\hline Fetus & 110 & 0.8 \\
\hline Proband & 90 & 0.2 \\
\hline Mother & 360 & 2.3 \\
\hline Father & 1240 & 67 \\
\hline Control & 3950 & 195 \\
\hline
\end{tabular}

${ }^{1}$ nmoles of substrate hydrolyzed per hr per mg protein.

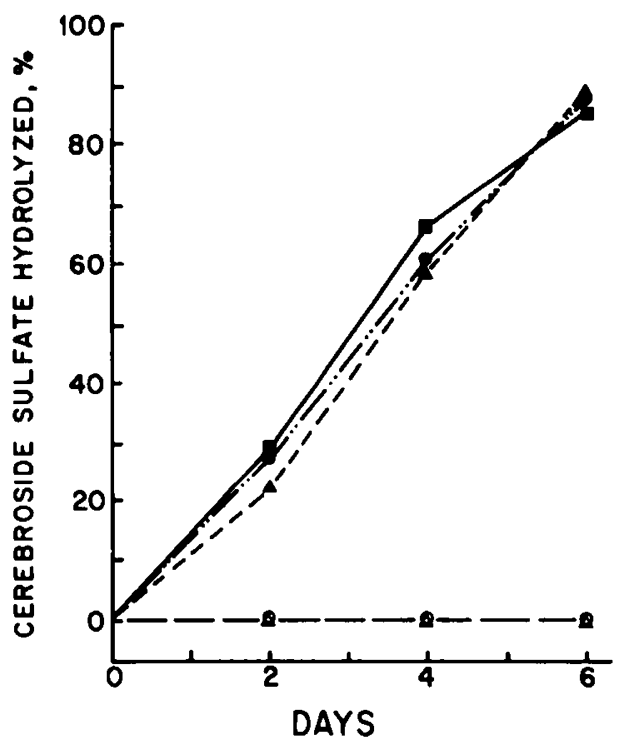

Fig. 2. The response of growing fibroblasts to the cerebroside sulfate loading test. Fetus $(\Delta)$; proband $(O)$; mother $(\Theta)$; father $(\Delta)$; control $(\square)$.

Table 6. Intracellular cerebroside sulfate of fibroblasts after the loading test

\begin{tabular}{lcc}
\hline & Cells & Cerebroside sulfate $^{1}$ \\
\hline Fetus & 37.4 \\
Proband & 26.5 \\
Mother & 4.0 \\
Father & 5.5 \\
Control & 8.8 \\
\hline
\end{tabular}

${ }^{1}$ nmoles per mg protein.

\section{DISCUSSION}

Prenatal diagnosis of MLD and its differentiation from pseudo arylsulfatase $\mathbf{A}$ deficiency was established by the cerebroside sulfate-loading test on cultured amniotic fluid cells. Distinguishing between pseudodeficiency and sulfatide lipidosis was not possible 
by the usual enzyme assays. The loading test proved to be quite effective with amniotic fluid cell cultures and provided a means for differentiation of the two potential enzyme deficient phenotypes in the fetus.

Previous cerebroside sulfate loading tests had been carried out on monolayer fibroblast cultures $(8,19,20)$, and it was uncertain whether the test would be effective in cultured amniotic fluid cells. The concerns included factors such as low cell population, a possible lack of incorporation of sulfatide by nonfibroblastic cells, and the low intrinsic enzyme activity of cultured amniotic fluid cells. The results indicated that such apprehensions were unfounded. Cerebroside sulfate hydrolysis by control cultured amniotic fluid cells was clearly demonstrated. The failure of hydrolysis and concomitant accumulation of sulfatide in the at-risk cells was equally clear. There was no equivocation in the conclusion that the fetus had the MLD rather than the pseudodeficiency phenotype.

The absence of neurological dysfunction in individuals with pseudo arylsulfatase A deficiency may seem enigmatic. Normal function despite apparent severe enzyme deficiency can be explained by assuming that arylsulfatase $A$ is normally present in amounts greatly exceeding physiological needs. We have shown that fibroblasts from a subject who first showed symptoms of MLD at age 16 contained about $1 \%$ of the cerebroside sulfatase activity of control cells (12). If such a small amount of enzyme allowed this individual to remain symptom-free into young adulthood, it is not surprising that the 2 to $10 \%$ of control enzyme levels seen in pseudodeficient subjects is indeed ample for sustained normal function.

Several explanations have been offered for the genetic basis of pseudo arylsulfatase A deficiency. Dubois et al. (3) postulated that pseudo deficiency could result from "a variant allele, regulatory or structural, on a different chromosome which affects expression of enzyme activity," or from "a single dominant phenotype different from "classical' MLD." Langenbeck et al. (13) disputed the logic of either hypothesis: the first because unnecessary assumptions were required and the second because most deficiences are inherited recessively. They proposed a third, simpler hypothesis based on the occurrence of another allele for the structural gene of arylsulfatase $\mathbf{A}$ which codes for enzyme with reduced activity. The latter parallels our view. By this hypothesis, the pseudodeficient mother in the present pedigree would be a mixed heterozygote of the late infantile MLD and the PD (pseudodeficiency) alleles. Only the PD allele allows production of functional enzyme so her enzyme level is 2 to $10 \%$ of normal. The father with about half-normal enzyme is presumably a usual heterozygote with the normal and late infantile MLD alleles. Heterozygotes of the normal and PD alleles would have enzyme levels 50 to $60 \%$ of normal, so biochemically they would be essentially identical with the usual MLD heterozygote. The homozygote of the PD allele would have twice the enzyme of the mixed heterozygote. The precision of arylsulfatase $A$ determinations in this depressed range is low because the breakthrough of the incompletely inhibited arylsulfatase B becomes significant. Therefore, the two genotypes may be difficult to discriminate by biochemical tests.

Butterworth et al. (2) recently identified a family with low arylsulfatase $A$ activity without MLD by leukocyte and fibroblast analysis. The proband is undoubtedly a mixed heterozygote of the MLD and PD allotypes. Now there are 6 such families in the literature, and we are aware of at least 2 additional families. We thus suspect that the frequency of the PD allele may be equal to or higher than the frequency of the MLD allele. It had been suggested that if cultured amniotic fluid cells in the prenatal diagnosis for MLD should show a deficiency of arylsulfatase $A$, then the parental enzyme profile should be examined for possible occurrence of the PD allele (15). We urge rather a routine early examination of the enzyme profile in all parents with pregnancies at risk for MLD. Early detection of pseudodeficiency families will facilitate preparation for the cerebroside sulfate loading test.

\section{REFERENCES AND NOTES}

1. Baum, H., Dodgson, K. S., and Spencer, B.: The assay of arylsulphatases A and $B$ in human urine. Clin. Chim. Acta, 4: 453 (1959).

2. Butterworth. J.. Broadhead, D. M., and Keay, A. J.: Low arylsulphatase A activity in a family without metachromatic leukodystrophy. Clin. Genet., 14 : 213 (1978)

3. Dubois, G., Harzer, K., and Baumann, N.: Very low arylsulfatase $A$ and cerebroside sulfatase activities in leukocytes of healthy members of metachromatic leukodystrophy family. Am. J. Hum. Genet., 29: 191 (1977).

4. Dubois, G., Turpin, J. C.. and Baumann, N.: Absence of ASA activity in healthy father of a patient with metachromatic leukodystrophy. N. Engl. J. Med., 293: 302 (1975).

5. Dulaney, J. T., and Moser, H. W.: Sulfatide lipidosis: metachromatic leukodystrophy. In: J. B. Stanbury, J. B. Wyngaarden. D. S. Frederickson: The Metabolic Basis of Inherited Disease. 4th ed. pp. 770-809 (McGraw-Hill Book Co.. New York, 1978).

6. Fluharty, A. L., Davis, M. L., Kihara, H., and Kritchevsky, G.: Simplified procedure for preparation of ${ }^{35}$ S-labeled brain sulfatide. Lipids, 9: 865 (1974).

7. Fluharty, A. L., and Edmond, J.: Arylsulfatases A and B from human liver. Methods Enzymol., 50: 537-547 (1978).

8. Fluharty, A. L., Stevens, R. L., and Kihara, H.: Cerebroside sulfate hydrolysis by fibroblasts from a metachromatic leukodystrophy parent with deficient arylsulfatase A. J. Pediatr., 92: 782 (1978).

9. Folch. J., Lees, M., and Sloane-Stanley, G. H.: A simple method for the isolation and purification of total lipids from animal tissues. J. Biol. Chem., 226: 497 (1957).

10. Harzer, K., Zahn, V., Stengel-Rutkowski, S., and Gley, E. O.: Pränatale Diagnose der metachromatischen Leukodystrophie. Disch. Med. Wochenschr., 100:951 (1975).

11. Kihara, H., Fluharty, A. L., and Kaback, M. M.: Unpublished results.

12. Kihara, H., Porter, M. T., and Fluharty, A. L.: Enzyme replacement in cultured fibroblasts from metachromatic leukodystrophy. In: R. J. Desnick, R. W. Bernlohr, W. Krivit: Enzyme Therapy in Genetic Diseases. Original Article Series, Vol. 9. pp. 19-26 (Williams \& Wilkins, Baltimore. 1973).

13. Langenbeck, V., Dunker, P., Heipertz, R., and Pilz, H.: Inheritance of metachromatic leukodystrophy. Am. J. Hum. Genet., 29: 638 (1977).

14. Leroy, J. G., Van Elsen, A. F., Martin, J. J., Dumon, J. E., Hulet, A. E., Okada. S., and Navarro, O.: Infantile metachromatic leukodystrophy: confirmation of a prenatal diagnosis. N. Engl. J. Med., 288: 1365 (1973).

15. Lott, I. T., Dulaney, J. T., Milunsky, A., Hoefnagel, D., and Moser, H. W.: Apparent biochemical homozygosity in two obligatory heterozygotes for metachromatic leukodystrophy. J. Pediatr., 89: 438 (1976).

16. Lowry, O. H., Rosebrough, N. J., Farr, A. L., and Randall, R. J.: Protein measurement with the Folin phenol reagent. J. Biol. Chem., 193: 265 (1951)

17. Nadler, H. L., and Gerbie, A. B.: Role of amniocentesis in the intrauterine detection of genetic disorders. N. Engl. J. Med., 282: 596 (1970).

18. Porter, M. T., Fluharty, A. L., de la Flor, S. D., and Kihara, H.: Cerebroside sulfatase determination in cultured human fibroblasts. Biochim. Biophys. Acta, 258: 769 (1972).

19. Porter, M. T., Fluharty, A. L., Harris, S. E., and Kihara, H.: The accumulation of cerebroside sulfates by fibroblasts in culture from patients with late infantile metachromatic leukodystrophy. Arch. Biochem. Biophys., I38: 646 (1970).

20. Porter, M. T., Fluharty, A. L., Trammell, J., and Kihara, H.: A correlation of intracellular cerebroside sulfatase activity in fibroblasts with latency in metachromatic leukodystrophy. Biochem. Biophys. Res. Commun., 44: 660 (1971).

21. Rattazzi, M. C., and Davidson, R. G.: Prenatal diagnosis of metachromatic leukodystrophy by electrophoetic and immunologic techniques. Pediatr. Res., Il: 1030 (1977).

22. Simpson, N. E., Dallaire, L., Miller, J. R., Siminovich, L., Hamerton, J. L., Miller, J., and McKeen, C.: Prenatal diagnosis of genetic disease in Canada; report of a collaborative study. Can. Med. Assoc. J.. 115: 739 (1976)

23. van der Hagen, C. B., Børresen, A. L., Molne, K., Oftedal, G., Bjøro, K., and Berg. K.; Metachromatic leukodystrophy. I. Prenatal detection of arylsulphatase A deficiency. Clin. Genet., 4: 256 (1973).

24. Wiesmann, U. N., Meier, C., Spycher, M. A., Schmid, W., Bischoff, A., Gautier, E., and Herschkowitz, N.: Prenatal metachromatic leukodystrophy. Helv. Paediatr. Acta, 30: 31 (1975).

25. Informed consents were obtained for the various specimens used.

26. The authors wish to thank Dr. P. G. McDonough for the amniocentesis, Dr. J. R. Byrd for culture of amniotic fluid cells, Ms. G. Johnson for technical assistance, and Drs. H. A. Taylor and H. L. Nadler for confirming the deficiency of enzyme activity in cultured amniotic fluid cells.

27. Requests for reprints should be addressed to: Hayato Kihara, Pacific State Hospital, P.O. Box 100-R, Pomona, CA 91766 (USA).

28. This research was supported by the NIH Grants NS-11665, HD-4612 and RR5365 and the National Foundation-March of Dimes Grant C-237.

29. Received for publication March 6, 1979.

30. Accepted for publication April 26, 1979 